\title{
Effect of Task-Oriented Training on Upper Extremity Function for Patients with Spinal Cord and Traumatic Brain Injuries: Systematic Review
}

\author{
MOHAMED A. HASSANIN, M.Sc.*; MAYA G. ALY, Ph.D.** and GEHAN M. AHMED, Ph.D.* \\ The Departments of Physical Therapy for Neuromuscular Disorders \& its Surgery* and Pediatric Physical Therapy**, \\ Faculty of Physical Therapy, Cairo University, Giza, Egypt
}

\begin{abstract}
Background: Tetraplegia that results from cervical injury is the most frequent neurologic category after spinal cord injury (SCI) and causes substantial disability. Traumatic Brain injury (TBI) is a shock or a penetrating injury to the head that disrupts the brain function leading to various impairments including upper limb dysfunction. Improving arm and hand function after these injuries is a major priority of rehabilitation due to its reflect on mobility, independency and quality of life. Advances of treatment approaches and technology have been introduced in research work; one of these approaches is task-oriented training (TOT).
\end{abstract}

Aim of Study: This systematic review aims to find out the evidence on the effectiveness of TOT to improve the upper limb functions among patients with SCI and TBI.

Material and Methods: This systematic review performed using the PubMed, Cochrane Central Register of Controlled Trials, Physiotherapy Evidence Database (PEDro) and the Egyptian Knowledge Bank (EKB) search engines and the associated keywords. The methodological quality assessment was done by two reviewers using PEDro scale. Random effect model and standardized mean differences were used for metaanalyses.

Results: The search identified 8,424 records, of which only two trials were selected as eligible. Quality appraisal revealed the trials were of good or fair quality.

Conclusion: This systematic review suggests moderate level of evidence for non-significant effect of Task-oriented training in improving upper limb function and hand dexterity in patients with spinal cord injuries and further primary research is recommended for both SCI and TBI.

Key Words: Spinal cord injuries - Traumatic brain injuries - Task-oriented - Upper extremity - Hand.

\section{Introduction}

SPINAL Cord Injury (SCI) occurs when the spinal cord is damaged as a result of trauma, disease

Correspondence to: Dr. Mohamed A. Hassanin, E-Mail: mohamed.hassanin@pt.cu.edu.eg processes, vascular compromise, or congenital neural tube defect. Congruently, Traumatic Brain injury (TBI) is a shock or a penetrating injury to the head that disrupts the brain function [1]. The severity of such an injury may range from mild to severe and can be deduced by manifestations they cause as coma, mental dysfunction, sensory disturbances, autonomic dysfunctions and motor problems (tetraplegia or paraplegia) depending on the extent and the location of the damage. The most common, most deadly and most disabling motor problem is tetraplegia (partial or total loss of sensory or motor function of upper, lower extremities and/or trunk) due to its reflect on arm and hand function that affects independency, mobility and quality of life [2-6]

Despite the great advances in clinical management (including surgical decompression, pharmacology, and investigational efforts and rehabilitation), recovery of motor function of the upper extremity is still considered limited. Physical Therapy is mandatory in all settings treating TBI or SCI whether the severity of patients' conditions or the need of surgical intervention and retraining of the patients to boost their functional post injury gains or to prevent more complications that occur before and after surgeries help with improving patients' mobility and quality of life.

In this regard; along with the continuous evolution of motor control theories and their applications as well, Physical therapists have put a great trust with Task-Oriented training (TOT) to deal with some neurological disorders primarily cerebrovascular stroke after the delivered evidence of its effectiveness to improve upper and lower extremity functions among stroke patients $[6,7]$. The motivating evidence of TOT impact on some lower 
limb functions encouraged our team to establish this review aiming to find the level of evidence of effectiveness of TOT to improve the upper limb or hand dexterity functions among SCI \& TBI $[8,9]$

\section{Material and Methods}

This review was applied in agreement with the Preferred Reporting Items for Systematic Reviews and Meta-Analysis (PRISMA) 2020 statement 10.

Selection criteria with respect to PICO framework were randomized controlled trials (RCTs) and pilot RCTs, published in English; included adults diagnosed with SCI or TBI, complained from upper extremity or hand skill impairments. Unaccompanied TOT model was used to train upper extremity. Trials must have at least one outcome measure focusing on upper limb function or hand dexterity to evaluate the effect of the intervention.

Studies with dates prior to 2005 of design other than RCT or included combined interventions or outcomes targeting upper extremity or hand function, or unreported results of outcome measures; were excluded.

\section{1-Search strategy:}

The electronic search was carried out between May 2020 and January 2021 and was last updated at April 2021 in the following databases: Cochrane Central Register of Controlled Trials, Physiotherapy Evidence Database (PEDro), PubMed and Egyptian Knowledge Bank [EKB] databases. Moreover, manual search was executed in the library of Faculty of Physical Therapy, Cairo University and by searching the references of eligible studies. Also, the reference lists were checked and some authors were contacted to access their full text articles and were asked for more details regarding their studies.

The following descriptor terms mixed with Boolean operators were used in the electronic databases: "spinal cord injuries" OR "traumatic brain injuries AND ("task-oriented" OR "taskspecific" OR "repetitive task' OR "constrainedInduced' OR "motor learning" OR "game-based" OR "virtual reality' OR "robotics" OR "nintendowii") AND ("upper limb" OR "upper extremity" OR "hand"). The search was restricted to clinical trials from 2005 to 2021.

\section{2- Selection process and data collection:}

Search strategy was accomplished using the previous keywords on different databases then duplicated articles were excluded. Publicized stud- ies had titles and abstracts inspected. Then, the records, according to their eligibility, were classified into "possibly relevant" or "possibly irrelevant". Possibly relevant studies had references examined carefully to enrich the search.

Subsequently, Full text of included trials were studied and the decision of exclusion of records was taken. In case of different opinions of the two reviewers (M.A.H and M.G.A), the opinion of the third reviewer (G.A.N) denoted the final decision.

Reasons of omitting any "possible relevant" studies from the review analyses were categorized as one of the followings: (1) The study design was not Randomized Control Trial. (2) TOT was combined with any other intervention. (3) Not homogenous sample. (4) Results were not made public.

One reviewer (M.A.H) independently gathered the data from assigned records in extraction forms then the forms were revised by another reviewer (M.G.A.). The following data were documented in a data extraction form that was created corresponding to the reported items in Cochrane guide of data collection forms: Title of the study, author contact and publication details for any future updates, study aims, design, selection criteria, size and allocation of participants, types of interventions and treatment measures, comparisons, upper extremity function or hand dexterity outcome measures and results.

\section{3- Study risk of bias assessment:}

The bias assessment was implemented by two reviewers. The preferred scale was Physical Therapy Evidence Database (PEDro) scale which assesses studies against 11 criteria (e.g.: eligibility criteria, randomization, blinding, allocation concealment and other aspects). Each item is scored with one point if the study meets the criteria, except for criterion number 1 then categorizes them by score as follows: Excellent (9-10), good (6-8), fair (4-5), and poor $(<4)$. In case of disagreement, reviewers reached consensus by discussion and referral to the third reviewer. Interpretation of the results and determining the levels of evidence used to summarize the findings have been performed using levels of evidence scale 11 .

\section{4- Effect measures:}

The results section of each included study was examined and the conclusions of the findings were documented.

The mean difference and the standard deviation of the difference between pre- and post-intervention 
upper limb or hand dexterity functional tests were the main building unit of the effect estimate across the studies. Because the scale of measurement was different across the included studies, the pooled effect measure was expressed as the standardized mean difference (SMD) with 95\% Confidence Interval (CI) and inverse variance (IV).

The heterogeneity of the studies was determined and quantified using the between-study statistical heterogeneity $\mathrm{I}^{2}$ statistics test. Interpretation of the results and determining the levels of evidence used to summarize the findings had been performed using the modified Sackett's evidence scale.

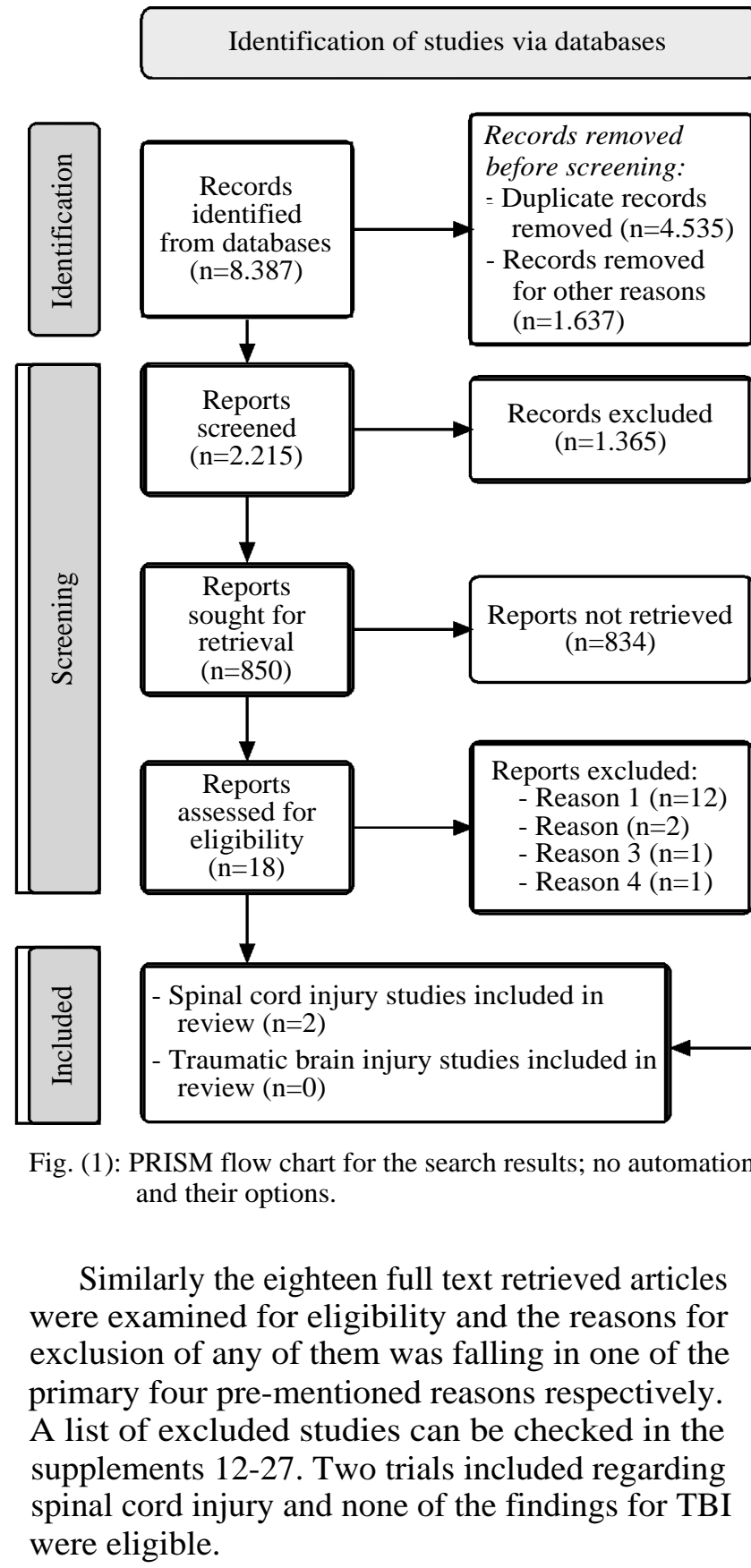

\section{Results}

The flow chart of this review (Fig. 1) shows that the search resulted in 8,424 articles, after examining them regarding the duplication and article topic; 2,215 were screened (by title and abstract) of which 1,365 were excluded due to lack of access to the full text or one of the pre-mentioned reasons of exclusion criteria which are: (1) The study design was not Randomized Control Trial. (2) TOT was combined with any other intervention. (3) Not homogenous sample. (4) Outcomes did not target upper limb or hand function. (5) Results were not made public.

Identification of studies via other methods

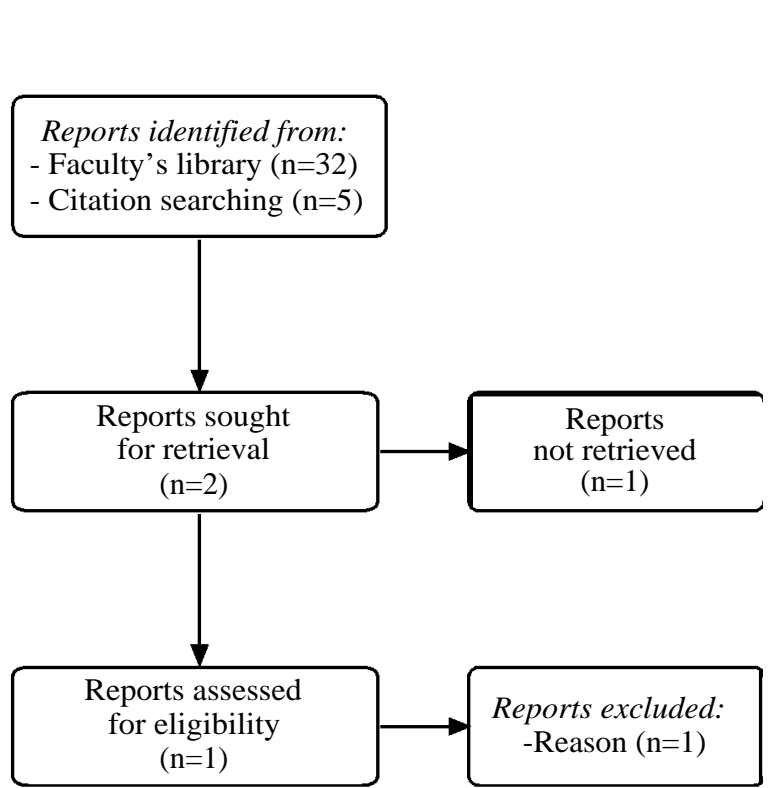


vention group of TOT not combined with other intervention and a control group (placebo or combined) $[28,29]$

Inclusion criteria of the participants were cervical SCI at or rostral to C7, age of 16 to 70 years, voluntary thumb movement (at least a visible twitch), and a diagnosis of spastic paresis for at least 1 year as a result of neurologically incomplete SCI. All of the included participants were classified on ASIA (2000 version) as grade C or Grade D 30. Table (2) shows demographics, participant number and other details. The intervention duration and intensity were unified as 2 hours per day, 5 days a week for 3 weeks. The intervention of the two trials was confined to massed practice (MP) in its standard format which is repetitive practice of functional tasks from five different movement categories (Gross UE Movement, Grip, Grip with Rotation, Pinch and Pinch with Rotation). The control group was either no treatment group (placebo) [28], or a combination of massed practice with somatosensory stimulation in its standard format (continuous delivery of trains of electrical stimulation over median nerve at wrist at intensity just below that required to cause observable twitch) [29].

Table (1): Methodological quality assessment using PEDro scale.

\begin{tabular}{lccccccccccccc}
\hline $\begin{array}{l}\text { Study } \\
\text { (author and year) }\end{array}$ & $1 *$ & 2 & 3 & 4 & 5 & 6 & 7 & 8 & 9 & 10 & 11 & Score & Quality \\
\hline $\begin{array}{l}\text { Beekhuizen and } \\
\text { Field Fote 2005 }\end{array}$ & N & Y & N & Y & Y & N & N & Y & N & Y & Y & 6 & Good \\
$\begin{array}{l}\text { Beekhuizen and } \\
\text { Field-fote 2008 }\end{array}$ & N & Y & N & Y & N & N & N & Y & N & Y & Y & 5 & Fair \\
\hline
\end{tabular}

*(1) Eligibility criteria, (2) Randomization, (3) Allocation concealment, (4) Baseline similarity, (5) Blinding of subjects, (6) Blinding of therapists, (7) Blinding of assessors, (8) Drop-out,(9) Analysis as allocation or by intention to treat, (10) Reporting between group statistical comparisons,(11) reporting point and variability measures. Each item is scored with one point if the study meets the criteria, except for criterion number 1 then categorizes them by score.

Table (2): Patient demographisc and characteristics of the included trials.

\begin{tabular}{|c|c|c|c|c|c|c|}
\hline Study & Intervention & $\begin{array}{l}\text { Number of } \\
\text { subjects }\end{array}$ & $\%$ Males & $\begin{array}{c}\text { Age } \\
\text { Mean (SD) }\end{array}$ & $\begin{array}{c}\text { Months } \\
\text { post injury } \\
\text { Mean (SD) }\end{array}$ & $\begin{array}{c}\text { Neurologica } \\
\text { level }\end{array}$ \\
\hline \multirow{4}{*}{$\begin{array}{l}\text { Beekhuizen and } \\
\text { Field Fote } 2008\end{array}$} & MP & 6 & $100 \%$ & $34.7(14.9)$ & $47.5(34.0)$ & $\begin{array}{l}17 \% \text { C } 4,33 \% \text { C5 } \\
33 \% \text { C6, } 17 \% \text { C7 }\end{array}$ \\
\hline & $\mathrm{MP}+\mathrm{S} \mathrm{S}$ & 6 & $83 \%$ & $47.8(20.0)$ & $66.8(264.0)$ & $\begin{array}{l}50 \% \text { C5, 33\% C6 } \\
17 \% \text { C7 }\end{array}$ \\
\hline & SS & 6 & $100 \%$ & $34.5(15.0)$ & $72.12(15.0)$ & $\begin{array}{l}66 \% \text { C5 }, 17 \% \text { C6, } \\
17 \% \text { C7 }\end{array}$ \\
\hline & Control & 6 & $83 \%$ & $33.3(6.9)$ & $82.6(49.9)$ & $\begin{array}{l}66 \% \text { C5 }, 17 \% \text { C6, } \\
17 \% \text { C7 }\end{array}$ \\
\hline \multirow{2}{*}{$\begin{array}{l}\text { Beekhuizen and } \\
\text { Field-fote } 2005\end{array}$} & MP & 5 & $100 \%$ & $45.0(10.3)$ & $58.6(56.2)$ & $20 \% \mathrm{C} 5,80 \% \mathrm{C} 6$ \\
\hline & $\mathrm{MP}+\mathrm{SS}$ & 5 & $80 \%$ & $32.6(8.0)$ & $29.6(12.1)$ & $\begin{array}{l}40 \% \text { C5, } 40 \% \text { C6, } \\
20 \% \text { C } 7\end{array}$ \\
\hline
\end{tabular}

MP:Massed Practice. SS: Somatosensory stimulation.

The outcome measures were outlined in the two trials as Wolf Motor Function Test (WMFT) timed task scores, Jebsen Taylor Hand Function Test scores (JTHFT), maximal pinch grip force and the intensity of the cortical stimulation required to evoke a motor threshold response $(50-100 \mathrm{~g} \mathrm{~V})$ in thenar muscles. Other outcome measures were added differently which were: Semmes-Weinstein monofilament sensory testing [28] and the motorevoked potentials (MEP) amplitude at $20 \%$ over motor threshold intensity (1.2x MT) [29]

With respect to the two trials, the impact of massed practice (type of TOT) seems to be positive among these trials on the pre-mentioned outcome measures. 
Comparison: Unilateral massed practice versus control:

The included studies reported the mean of the paired difference between pre and post-intervention values and standard error of the mean (SE) instead of the SD. The SD was calculated using the equation $\mathrm{SD}=\mathrm{SE} \times \mathrm{SQRT}(\mathrm{n})$, where $\mathrm{SQRT}$ is the square root of (n) which indicates the number of participants.

Task oriented training does not have significant effect on Jebsen Taylor's Hand Function Test in spinal cord injury patients compared to conventional therapy (SMD 1.23, 95\% CI from 2.62 to 0.16 ; $p=0.08 ; \mathrm{I}^{2}=50 \%$; random effect model) (Fig. 2).

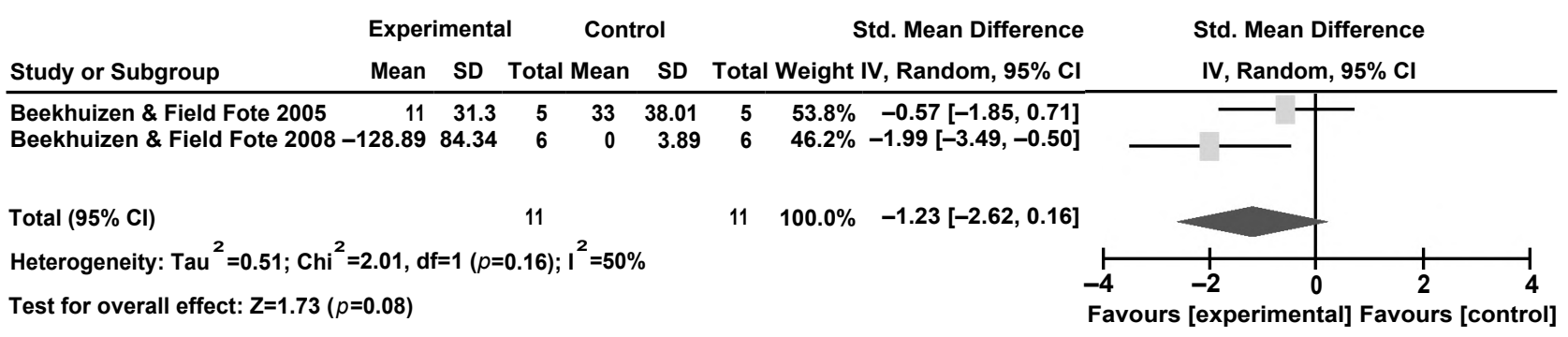

Fig. (2): Comparison between massed practice and control groups, outcome: Upper limb functional outcome (Created in Review Manager 5.4.1).

\section{Discussion}

Despite the low number of included studies, the results propose the positive impact of TOT on improving arm and hand functions in a select group of patients with cervical SCI, but the results must be interpreted with caution due to the small sample sizes and their reflect on patient limited demographics and characteristics.

Previous evidence regarding spinal cord injuries suggested that training of the upper limb following spinal cord injury leads to improvements in muscle strength, upper limb function and activities of daily living or quality of life $[\mathbf{1 5 , 1 6 ]}$. Some of them investigated the effects of some types of TOT without technology intrusion, others examined technology interference generally without specifying a training approach [31,32].

According to our literature search, the combination of TOT with other interventions appeals to be more famous for its promising results; a reason for its reputation among research assigned intervention rather than TOT alone and the fact of the major advances of technologies in the field seems to be motivating for researchers to engage them as a sort of unique intervention in their scientific work enrolling spinal cord injuries regarding lower extremities functions, gait and balance, contrary to upper extremity or hand functions $[33,34]$.

TBI consciousness level may limit the researchers to induce TOT in many instances which may be a great reason for the scarcity of studies intro- ducing a rehabilitation intervention to a pure sample of TOT beside the other limitations related to the condition.

The strengths of this review can be summed up into the extended search in databases and in date (16 years) and to be the first to include only randomized controlled trials which highlight the gap of research on this topic and encourage future research to confirm the evidence of effectiveness of TOT for cases of SCI and to get the evidence for TBI cases.

The limitations are language restrictions (only English publications) and very limited number of included studies that reached none for TBI.

Although TOT has been incubated as an umbrella approach for many treatment methods as constraint - induced movement therapy, game based therapy, dual tasking and others and has been offered as a module $[\mathbf{2 3 , 3 5 , 3 6 ]}$; its impact on upper limb function for patients with upper motor neuron lesions other than stroke (two of them is included in this review) needs further research targeting its effect alone with or without the use of modern technologies (e.g. Robotic devices and Virtual Reality procedures). This systematic review states moderate level of evidence according to modified Sackett's scale for the non-significant influence of Task-oriented training in improving upper limb function and hand dexterity among patients with spinal cord injuries and further well-designed RCTs are recommended for both spinal cord and traumatic brain injuries. 


\section{Conflict of Interest:}

Authors declare that there is no conflict of interest.

\section{Acknowledgments:}

Special thanks to Dr. Magdy Ibrahim, professor of Obstetrics and Gynecology, Faculty of Medicine, Cairo University, and director of research and biostatistics unit, medical education development center, Cairo University, for helping with statistical part of this research work and for advice towards our appreciating review.

\section{Funding:}

This research received no specific grant from any type of funding resources.

$$
\text { ID: 012/002938 }
$$

Supplements:

List of excluded possible relevant studies:

- Not a Randomized controlled trial:

1- Virtual Reality Environment with Haptic Feedback Thimble for Post Spinal Cord Injury Upper-Limb Rehabilitation (Gutiérrez, Á. et al. 2021).

2- Adaptive Virtual Reality Exergame for Individualized Rehabilitation for Persons with Spinal Cord Injury (Palaniappan S. M. et al., 2021).

3- Robot-Assisted Training of Arm and Hand Movement Shows Functional Improvements for Incomplete Cervical Spinal Cord Injury (Francisco G. E. et al., 2017).

4- Upper limb rehabilitation after spinal cord injury: A treatment based on a data glove and an immersive virtual reality environment (Dimbwadyo-Terrer I. et al., 2016).

5- Protocol of constraint-induced movement therapy for patients after traumatic brain injury (Zajc D. 2016).

6- Changes in hand muscle synergies in subjects with spinal cord injury: Characterization and functional implications (Zariffa J. et al., 2012).

7- Feasibility and efficacy of upper limb robotic rehabilitation in a subacute cervical spinal cord injury population (Zariffa J. et al., 2012).

8- ToCUEST: A task-oriented client-centered training module to improve upper extremity skilled performance in cervical spinal cord-injured persons (Spooren A.I.F. et al., 2011).

9- Evaluation of a task-oriented client-centered upper extremity skilled performance training mod- ule in persons with tetraplegia (Spooren A.I.F. et al., 2011).

10- Rehabilitation throughout lifespan: Clientcentred task-oriented modular therapy in cervical spinal cord injured patients (Spooren A.I.F. et al., 2011).

11- Constraint-induced movement therapy for recovery of upper-limb function following traumatic brain injury (Shaw S. E. et al., 2005).

12- Robot-mediated therapy for paretic upper limb of chronic patients following neurological injury (Posteraro F. et al., 2009).

\section{- Combined intervention:}

13- Effects of Combined Upper Limb Robotic Therapy in Patients with Tetraplegic Spinal Cord Injury (Jung J. H. et al., 2019).

14- Effect of massed practice and somatosensory stimulation on the upper extremity function in patients with incomplete cervical spinal cord injury (Nasser E.N. et al., 2014).

- No results reported:

15- Protocol for a Randomized Controlled Trial of CI Therapy for Rehabilitation of Upper Extremity Motor Deficit: The Bringing Rehabilitation to American Veterans Everywhere Project (Morris D. M. et al., 2019).

- No outcome measure for upper extremity or hand function:

16- Digital Gaming for Improving the Functioning of People with Traumatic Brain Injury: Randomized Clinical Feasibility Study (Välimäki M. et al., 2018).

\section{References}

1- Faul M., Xu L., Wald M.M. and CORONADO V.G.: Traumatic brain injury in the United States: Emergency department visits, hospitalizations and deaths 2002-2006, Centers for Disease Control and Prevention, National Center for Injury Prevention and Control Atlanta, 10, 2010.

2- National Spinal Cord Injury Statistical Center, Birmingham, Alabama. Spinal cord injury facts and figures at a glance. the journal of spinal cord medicine, 35 (4): 197 198, 2012. https://doi.org/10.1179/1079026812Z 00000000063

3- DAHLBERG A., KOTILA M., KAUTIAINEN H. and ALARANTA H.: Functional independence in persons with spinal cord injury in Helsinki. Journal of rehabilitation medicine, 35 (5): 217-220, 2003. https://doi.org/ $10.1080 / 16501970306092$

4- TRGOVCEVIC S., MILICEVIC M., NEDOVIC G. and JOVANIC G.: Health Condition and Quality of Life in 
Persons with Spinal Cord Injury. Iranian journal of public health, 43 (9): 1229-1238, 2014.

5- ALIZADEH A., DYCK S.M. and KARIMIABDOLREZAEE S.: Traumatic Spinal Cord Injury: An Overview of Pathophysiology, Models and Acute Injury Mechanisms. Frontiers in neurology, 10, 282, 2019. https://doi.org/10.3389/fneur.2019.00282

6- WINSTEIN C.J., WOLF S.L., DROMERICK A.W., LANE C.J., NELSEN M.A., LEWTHWAITE R., CEN S.Y., AZEN S.P. and Interdisciplinary Comprehensive Arm Rehabilitation Evaluation (ICARE) Investigative Team. Effect of a Task-Oriented Rehabilitation Program on Upper Extremity Recovery Following Motor Stroke: The ICARE Randomized Clinical Trial. JAMA, 315(6), 571581, 2016. https://doi.org/10.1001/jama.2016.0276.

7- MEHRHOLZ J., THOMAS S, KUGLER J, POHL M. and ELSNER B. Electromechanical-assisted training for walking after stroke. Cochrane Database of Systematic Reviews, Issue 10. 2020. Art. No.: CD006185. DOI: 10.1002/14651858.CD006185.pub5. Accessed 07 May 2021.

8- HOLANDA, L.J., SILVA P., AMORIM T.C., LACERDA M.O., SIMÃO C.R. and MORYA E. Robotic assisted gait as a tool for rehabilitation of individuals with spinal cord injury: a systematic review. Journal of neuroengineering and rehabilitation, 14 (1): 126, 2017. https://doi.org/ 10.1186/s12984-017-0338-7.

9- AMGAD M.A., NAWAL A.A. and IBRAHIM M.H.: Robotic-assisted locomotor training for walking in spinal cord injury patients: Systematic review. MD [dissertation]. Faculty of Physical therapy, Cairo University.

10- PAGE M.J., MCKENZIE J.E., BOSSUYT P.M., BOUTRON I., HOFFMANN T.C., MULROW C.D., et al.: The PRISMA 2020 statement: An updated guideline for reporting systematic reviews. BMJ, 372: n71, 2021. doi: $10.1136 /$ bmj.n71

11- SACKETT D.L., RICHARDSON W.L., ROSENBERG W., STRAUS E.S., HAYNES R.B. and LIVINGSTONE C.: Evidence-Based medicine. How to practice and Teach EBM. $2^{\text {nd }}$. Ed. Churchill Livingstone: New York. 2000/

12- GUTIÉRREZ Á., FARELLA N., GIL-AGUDO Á. and DE LOS REYES GUZMÁN A.: Virtual Reality Environment with Haptic Feedback Thimble for Post Spinal Cord Injury Upper-Limb Rehabilitation. Applied Science, 11 (6): 2476, 2021. https://doi.org/10.3390/app 11062476

13- PALANIAPPAN S.M., SURESH S., HADDAD J.M. and DUERSTOCK B.S.: Adaptive Virtual Reality Exergame for Individualized Rehabilitation for Persons with Spinal Cord Injury. In: Bartoli A., Fusiello A., editors. European Conference on Computer Vision (ECCV); 2020; Glasgow - United Kingdom. Springer, 518-535, 2020. https:// . doi.org/10.1007/978-3-030-66823-5 31.

14- MORRIS D.M., TAUB E., MARK V.W., LIU W., BRENNER L., PICKETT T., STEARNS-YODER K., BISHOPMCKAY S., TAYLOR A., REDER L., ADAMS T., RIMMER J., DEW D., SZAFLARSKI J., WOMBLE B., STEVENS L., ROTHMAN D. and USWATTE G.: Protocol for a Randomized Controlled Trial of CI Therapy for Rehabilitation of Upper Extremity Motor Deficit: The Bringing Rehabilitation to American Veterans Everywhere Project. The Journal of head trauma rehabilitation, 34 (4):
268-279, 2019. https://doi.org/10.1097/HTR 0000000000000460 .

15- JUNG J.H., LEE H.J., CHO D.Y., LIM J.E., LEE B.S., KWON S.H., KIM H.Y. and LEE S.J.: Effects of Combined Upper Limb Robotic Therapy in Patients With Tetraplegic Spinal Cord Injury. Annals of rehabilitation medicine, 43 (4): 445-457, 2019. https://doi.org/ 10.5535/arm.2019.43.4.445.

16- VÄLIMÄKI M., MISHINA K., KAAKINEN J.K., HOLM S.K., VAHLO J., KIRJONEN M., PEKURINEN V., TENOVUO O., KORKEILA J., HÄMÄLÄINEN H., SARAJUURI J., RANTANEN P., ORENIUS T. and KOPONEN A.: Digital Gaming for Improving the Functioning of People With Traumatic Brain Injury: Randomized Clinical Feasibility Study. Journal of medical Internet research, 20 (3): e77, 2018. https://doi.org/10.2196/jmir.7618.

17- FRANCISCO G.E., YOZBATIRAN N., BERLINER J., O'MALLEY M.K., PEHLIVAN A.U., KADIVAR Z., FITLE K. and BOAKE C.: Robot-Assisted Training of Arm and Hand Movement Shows Functional Improvements for Incomplete Cervical Spinal Cord Injury. American journal of physical medicine \& rehabilitation, 96 (10 Suppl 1): S171-S177, 2017. https://doi.org/10.1097/ PHM.0000000000000815.

18- DIMBWADYO-TERRER I., TRINCADO-ALONSO F., DE LOS REYES-GUZMÁN A., AZNAR M.A., ALCUBILLA C., PÉREZ-NOMBELA S., DEL AMAESPINOSA A., POLONIO-LÓPEZ B. and GIL-AGUDO Á.: Upper limb rehabilitation after spinal cord injury: A treatment based on a data glove and an immersive virtual reality environment. Disability and rehabilitation. Assistive technology, 11 (6): 462-467, 2016. https://doi.org/10.3109/ 17483107.2015.1027293.

19- ZAJC D.: Protocol of constraint-induced movement therapy for patients after traumatic brain injury. Poster presented at: the International Brain Injury Association's Eleventh World Congress on Brain Injury. The Hague World Forum. The Brain Injury, 30 (5-6) 636; Netherlands. 2016. DOI: $10.3109 / 02699052.2016 .1162060$.

20- NASSER M.E., REDA M.A., AWAD M.R., AMIN I.R. and ASSEM S.A.: Effect of massed practice and somatosensory stimulation on the upper extremity function in patients with incomplete cervical spinal cord injury. Alexandria Journal of Medicine. 50 (2), 189-196. 2014. https://doi.org/10.1016/j.ajme.2014.02.001.

21- ZARIFFA J., KAPADIA N., KRAMER J.L., TAYLOR P., ALIZADEH-MEGHRAZI M., ZIVANOVIC V., WILLMS R., TOWNSON A., CURT A., POPOVIC M.R. and STEEVES J.D.: Feasibility and efficacy of upper limb robotic rehabilitation in a subacute cervical spinal cord injury population. Spinal cord, 50 (3): 220-226, 2012. https://doi.org/10.1038/sc.2011.104.

22- ZARIFFA J., STEEVES J. and PAI D.K.: Changes in hand muscle synergies in subjects with spinal cord injury: characterization and functional implications. The journal of spinal cord medicine, 35 (5): 310-318, 2012. https://doi.org/10.1179/2045772312Y.0000000037.

23- SPOOREN A.I., JANSSEN-POTTEN Y.J., KERCKHOFS E., BONGERS H.M. and SEELEN H.A.: To CUEST: A task-oriented client-centered training module to improve upper extremity skilled performance in cervical spinal cord-injured persons. Spinal cord, 49 (10): 1042-1048, 2011. https://doi.org/10.1038/sc.2011.52. 
24- SPOOREN A.I., JANSSEN-POTTEN Y.J., KERCKHOFS E., BONGERS H.M. and SEELEN H. A.: Evaluation of a task-oriented client-centered upper extremity skilled performance training module in persons with tetraplegia. Spinal cord. 49 (10): 1049-1054, 2011. https://doi.org/ 10.103 8/sc.2011.54.

25- SPOOREN A.I.F., JANSSEN-POTTEN Y.J.M., BONGERS H.M.H. and SEELEN H.A.M. Rehabilitation throughout Lifespan: Client-Centred Task-Oriented Modular Therapy in Cervical Spinal Cord Injured Patients. Poster presented at: World Physical Therapy, Amsterdam, Netherlands, 2011.

26- SHAW S.E., MORRIS D.M., USWATTE G., McKAY S., MEYTHALER J.M., and TAUB E.: Constraint-induced movement therapy for recovery of upper-limb function following traumatic brain injury. Journal of rehabilitation research and development, 42 (6): 769-778, 2005. https://doi.org/1 0.1682/j rrd.2005. 06.0094.

27- POSTERARO F., MAZZOLENI S., ALIBONI S., CESQUI B., BATTAGLIA A., DARIO P. and MICERA S.: Robotmediated therapy for paretic upper limb of chronic patients following neurological injury. Journal of rehabilitation medicine, 41 (12): 976-980, 2009. https://doi.org/ 10.2340/16501977-0403.

28- BEEKHUIZEN K.S. and FIELD-FOTE E.C.: Sensory stimulation augments the effects of massed practice training in persons with tetraplegia. Archives of physical medicine and rehabilitation, 89 (4): 602-608, 2008. https://doi.org/10.1016/j.apmr.2007.11.021.

29- BEEKHUIZEN K.S. and FIELD-FOTE E.C.: Massed practice versus massed practice with stimulation: Effects on upper extremity function and cortical plasticity in individuals with incomplete cervical spinal cord injury. Neurorehabilitation and neural repair, 19 (1): 33-45, 2005. https://doi.org/10.1177/1545968305274517.

30- American Spinal Injury Association, International Medical
Society of Paraplegia. International standards for neurological and functional classification of spinal cord injury. Chicago: American Spinal Injury Association, 2000.

31- SPOOREN A.I., JANSSEN-POTTEN Y.J., KERCKHOFS E. and SEELEN H.A.: Outcome of motor training programmes on arm and hand functioning in patients with cervical spinal cord injury according to different levels of the ICF: a systematic review. Journal of rehabilitation medicine, 41 (7): 497-505, 2009. https://doi.org/ 10.2340/16501977-0387.

32- LU X., BATTISTUZZO C.R., ZOGHI M. and GALEA M.P.: Effects of training on upper limb function after cervical spinal cord injury: A systematic review. Clinical rehabilitation, 29 (1): 3-13, 2015. https://doi.org/ $10.1177 / 0269215514536411$.

33- ANDERSON A., ALEXANDERS J., ADDINGTON C. and ASTILL S.: The effects of unimanual and bimanual massed practice on upper limb function in adults with cervical spinal cord injury: A systematic review. Physiotherapy, 105 (2): 200-213, 2019. https://doi.org/10.1016 . ji.physio.2018.10.003.

34- YOZBATIRAN N. and FRANCISCO G.E.: Robot-assisted Therapy for the Upper Limb after Cervical Spinal Cord Injury. Physical medicine and rehabilitation clinics of North America, 30 (2): 367-384, 2019. https://doi.org/ 10.1016/j.pmr.2018.12.008.

35- O'SULLIVAN S.B., SCHMITZ T., ACKERMAN P., ARDOLINO E., ATRICE M. and BARBAS J.: Improving Functional Outcomes in Physical Rehabilitation. 2 nd ed. Philadelphia, United States: F.A. Davis Company, 2010

36- ORTIZ-CATALAN M., NIJENHUIS S., AMBROSCH K., BOVEND'EERDT T., KOENIG T. and LANGE B.: Chapter 13: Virtual reality. Emerging therapies in neurorehabilitation. Biosystems and Biorobotics. Springer, Spain, 257, 2014.

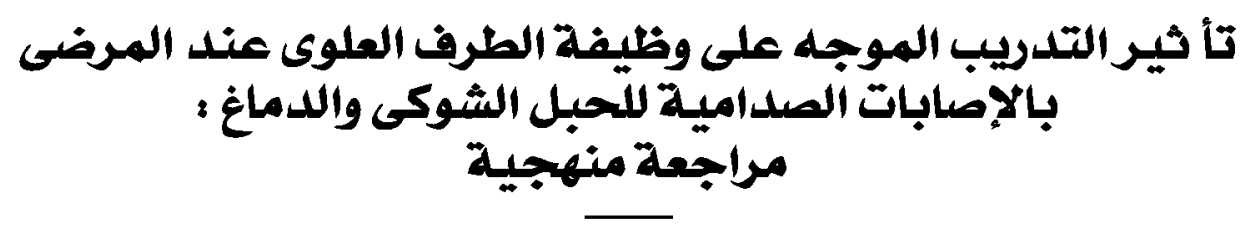

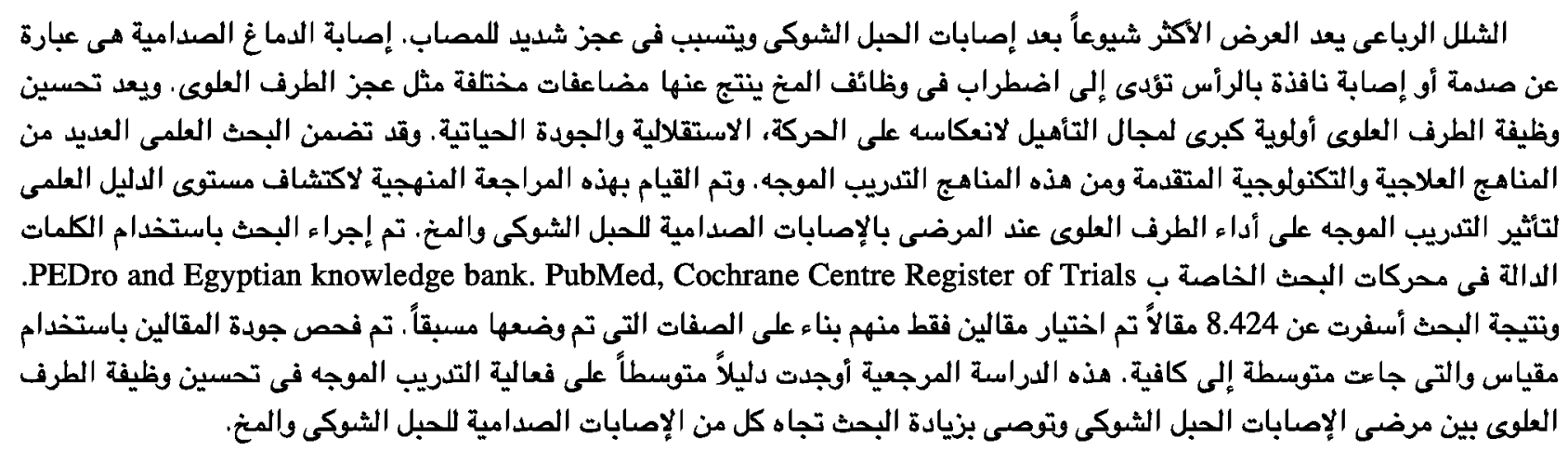

